RESEÑAS 

REVISTA DE DERECHO UNED, NÚM. 27, 2021

\title{
GONZALO J., BASSO, DETERMINACIÓN JUDICIAL DE LA PENA Y PROPORCIONALIDAD \\ CON EL HECHO, MARCIAL PONS, MADRID, 2019, 429, PÁGINAS., ISBN: 9788491236146.
}

\author{
Roberto Cruz Palmera \\ Doctor en Derecho \\ Profesor de Derecho Penal \\ rcruz.3@alumni.unav.es
}

La prestigiosa editorial Marcial Pons ha publicado la monografía del profesor de Derecho Penal, Gonzalo J. Basso, que lleva como título «Determinación judicial de la pena y proporcionalidad con el hecho».

La publicación se corresponde, básicamente, con la tesis doctoral elaborada por el autor ${ }^{1}$. La investigación contó con la dirección del profesor Dr. Manuel Cancio Meliá, catedrático de Derecho Penal de la Universidad Autónoma de Madrid, quien, conjuntamente, prologa el libro. El prologuista nos adelanta algunas de las virtudes de este trabajo: «El texto lleva a cabo una revisión de conjunto de la teoría de la medición de la pena, centrada en las últimas décadas y desarrollada respecto de las principales jurisdicciones de Occidente, proponiendo una reorientación de esta teoría con base en una fundamentación sistemática original. Este libro [...] abre la puerta a un "sistema de fuentes" para la medición de la pena mucho más complejo y matizado, en el que pueden y deben tenerse en consideración elementos provenientes de la dogmática, el proceso penal, el Dere-

1 Título de la tesis: «Lo general y lo particular en la atribución judicial del castigo estatal. Un estudio sobre el anclaje de la pena concreta en la escala abstracta con sustento en la distinción entre proporcionalidad cardinal y ordinal», defendida el 30 de junio de 2017. 
cho penal internacional o el Derecho constitucional, junto con los que se infieren de las teorías de la pena». Cancio Meliá también nos anticipa uno de los méritos de este trabajo, la precisión, robustez y originalidad en las aportaciones efectuadas por el autor.

La monografía se estructura en introducción, cuatro apretados capítulos y las conclusiones. En la introducción Gonzalo J. Basso, expone la necesidad de ofrecer un modelo teórico que sirva de base tanto para la orientación como para la guía de la actividad del operador judicial en el ámbito de la imposición de la pena estatal. En tal sentido, expone que dicho modelo está supeditado, en lo esencial, al marco de la determinación legal de la sanción en sentido estricto para casos concretos.

La obra se caracteriza por su robustez, Gonzalo J. Basso abarca en su trabajo la inmensa mayoría de aspectos tanto principales como accesorios relacionados en la teoría de la pena. Su autor empela un léxico preciso, claro; encontrándose el lector ante una obra solvente que no pasará desapercibida en la dotrina científica.

A mi juicio, y si no lo malinterpreto, la propuesta de Basso es la siguiente: la elaboración de un modelo orientado a la aplicación igualitaria de sanciones (o penas) moderadas. Dicho modelo ofrece al operador judicial un conjunto de medidas para la elaboración de juicios valorativos e igualitarios tanto en términos cardinales como ordinales.

En el Capítulo I «La determinación judicial de la pena en sistemas de Derecho penal continental, internacional y anglosajón», Basso presenta y explica, entre otros tópicos, un conjunto de preceptos reguladores de la determinación de la pena en destinos sistemas jurídicos: España, Alemania, Argentina, Italia; además, ofrece una presentación sobre la determinación de la pena en el ámbito estadounidense (pp. 31-75).

En el Capítulo II, «Enfoques teóricos de determinación judicial de la pena», profundiza acerca de la problemática de la imprecisión del concepto de la culpabilidad, en clave con la necesidad de establecer penas concretas. Su autor sostiene que tanto el punto límite como el máximo de la culpabilidad conforman lugares punitivos imprecisos e hipotéticos, por tanto, el único camino factible es afirmar la dificultad de determinar los aspectos democráticos del propio marco penológico de la culpabilidad (pp. 82-237).

En el Capítulo III, titulado «Punto de partida», empieza la segunda parte del trabajo: determinación judicial de la pena y propor- 
cionalidad con el hecho: un enfoque alternativo. Su autor expone un conjunto de temas como el concepto de injusto y culpabilidad, la naturaleza jurídica del acto de atribución judicial, los fines de la pena; entre otros. Concluye marcando la necesidad de establecer un concepto de injusto que reconozca la relevancia de los aspectos sistemáticos, comunicativos y materiales adheridos a la culpabilidad como juicio de atribución, aspectos necesarios para atribuir una media o sanción justa en términos democráticos (pp. 271-300).

En el Capítulo IV «Proporcionalidad cardinal y proporcionalidad ordinal en la determinación judicial de la pena», Basso profundiza en la denominada pena exacta, así como en la proporcionalidad ordinal en la atribución judicial. Propone un modelo alternativo de atribución judicial estructurado en los conceptos de proporcionalidad penal cardinal y ordinal, esa es su tesis. Su modelo pretende aumentar la capacidad de rendimiento en los sistemas de medición del castigo estatal. Conjuntamente, por otra parte, con relación a su noción de proporcionalidad cardinal, afirma que debe interpretarse y aplicarse en el marco jurídico de la pena individual, pero en escala abstracta (pp. 301-383).

En definitiva, el escrupuloso trabajo del profesor Gonzalo J., Basso, expuesto tan ágilmente en escasas páginas, nos proporciona un instrumento de reflexión y análisis sobre la estructuración de los alcances para la atribución interpretativa a la hora de determinar una pena democrática. 
